\title{
COORDINATED RESEARCH PROJECT “DEVELOPMENT OF RADIOMETRIC METHODS AND MODELLING FOR MEASUREMENT OF SEDIMENT TRANSPORT:
}

TWO PERUVIAN CASE STUDIES IN THE FRAME OF THE PROJECT

\author{
Carlos SEBASTIAN CALVO \\ Universidad Ricardo Palma \\ carlos.sebastian@urp.edu.pe
}

\section{ABSTRACT}

The first case study, namely Evaluation of leakages in Peruvian mining tail deposits by the aid of radiotracers, corresponds to the evaluation of leakages in two tailing deposits have been performed in a Peruvian Mining Company, in Cusco-Peru, through the injection of tritiated water as a proper tracer, and the use of isotope and chemical techniques, in order to confirm the existence of filtrations in the neighborhood of such tailing deposits. The objective of the study was to establish a cause-effect mechanism between the two mineral tailing deposits and its corresponded influence area, as probably receipt bodies of contamination.

As a result of the intensive operation, it was established a cause-effect mechanism between the deposits and its corresponded influence area as a receipt bodies of contamination by tailing elements.

The second case study, namely "Determination of flow velocities in groundwater by the aid of tracer techniques" corresponds to the evaluation of the groundwater resources in Ica Region at the southern Peru, and reports methodologies and techniques developed for on-site artificial tracer aided measurements of groundwater flow velocities. Horizontal flows are computed through labeling of the whole water column which is coated with a holed pipe in its entire length, below the piezometric level. Concentration monitoring inside the well, is performed prior to the experiment. The objective of the study was to determine the velocity of water flow, by the aid of tracer techniques, as applied to single well, in order to contribute to the solution of the problem of the aquifer management. 


\section{Case study I: EVALUATION OF LEAKAGES IN PERUVIAN MINING TAIL DEPOSITS BY THE AID OF RADIOTRACERS}

\section{INTRODUCTION} valuation of leakages in two tailing deposits have been performed in a
Peruvian Mining Company, in Cusco-Peru, through the injection of tritiated
water as a proper tracer, and the use of isotope and chemical techniques,
in order to confirm the existence of filtrations in the neighborhood of such
tailing deposits. As a result of the intensive operation, it could be established a
cause-effect mechanism between the deposits and its corresponded influence
area as a receipt bodies of contamination by tailing elements.

The objective of the study was to establish a cause-effect mechanism between the two mineral tailing deposits and its corresponded influence area, as probably receipt bodies of contamination.

The applied methodology consisted in:

a. Establishment of the monitoring points.

b. Analysis of the existing information, including environmental Impact reports, from previous studies, as well as complementary data collected in a preliminary inspection visit to the place under study.

c. Determination of the Activity for the radioactive tracer to be used.

d. Injection of tracer.

e. Sampling in the previously defined points where naturally water flows remains.

f. Monitoring, detection, measuring, sampling and quantification of the tracer in the places where water flows appears as possible contribution of leakages from the tailing deposits.

\section{FUNDAMENTALS}

A conservative assumption is done, that the injected tracer is naturally diluted into a defined volume of the system which is moving following a flow pattern. La first part of the calculation is to estimate an expected dilution volume. Most common flow patterns assume a radial geometry. This estimative has given goods and robust results in a wide field of situations. ${ }^{[1]}$

The smallest required injection pulse is generally the amount of the necessary tracer to produce an average concentration of 10 times the Minimum Detection Limit in such a dilution volume.

The dilution volume $\mathrm{Vd}$, can be computed in advance by the aid of a radial approximation to the geometry of the flow pattern. If $r$ is the distance from the input of the tracer, $f$ the porosity of the formation, $h$ the thickness and $S_{w}$ the water saturation, then the volume considered by a radial approximation will be: 


$$
\mathrm{V}_{\mathrm{d}}=\pi \mathrm{r}^{2} \mathrm{hS}_{\mathrm{w}} \phi
$$

The sensitivity of detection for a given radioisotope is computed from the environment background without any tracer presence, for a geometry factor equal to one. The Minimum Detection Limit (MDL), is the calculated value in two standard deviations, and is generally called as the one of the confidence level of $95 \%$. The minimum tracer activity, $A$, enough to be higher than 10 times the MDL is given by:

$$
\mathrm{A} \geq 10 \times \mathrm{MDL} \times \mathrm{V}_{\mathrm{d}}=\frac{20 \sqrt{2 \mathrm{C}_{\mathrm{b}}}}{\mathrm{EtV}_{\mathrm{s}}} \times \mathrm{V}_{\mathrm{d}}
$$

where $C_{b}$ es el background counting rate by unit time, $t$, $E$ is the counting efficiency of detector for the given radioisotope, $V_{s}$ is the volume of the sample and $V_{d}$ is the dilution volume of the water field.

Considering a maximum radio of $3,5 \mathrm{Km}$. given by the most distant monitoring point, taking into account the dimensions of the tailing deposits, and assuming conservative excess values for $S_{w}$, and $h$, the labeled volume considering the neighborhood of the tailing deposit would be:

$V_{d}=3.1416 \times(3500 \mathrm{~m} .)^{2} \times 6 \mathrm{~m} . \times 0.3 \times 0.4=27143424 \mathrm{~m}^{3}$

For each $1 \mathrm{Ci}$ entering the aquifer, we found the following average concentration, $\mathrm{C}_{\mathrm{m}}$ :

$C_{m}=10^{6} \mathrm{mCi} / 27143424 \mathrm{~m}^{3}=0.037 \mathrm{mCi} / \mathrm{m}^{3}$, Non detectable directly by liquid scintillation, and it would be necessary an enrichment.

But, the recommended necessary activity is:

$A \geq 10 \times M L D \times V_{d}$

$\mathrm{A} \geq 10 \times 1.5 \times 10^{-2} \mathrm{~Bq} / \mathrm{L} \times 27143424 \times 10^{3} \mathrm{~L}$

$A \geq 407151360 \mathrm{~Bq}(1.1 \mathrm{Ci})$

With this result, we found the follo+wing average concentration, $C_{m}$ :

$C_{m}=1.1 \times 10^{6} \mathrm{mCi} / 27143424 \mathrm{~m}^{3}=0.044 \mathrm{mCi} / \mathrm{m}^{3}$, just a little bit detectable directly by liquid scintillation. For safe, we use $2.5 \mathrm{Ci}$. With this value, we obtain the following average concentration:

$C_{m}=2.5 \times 10^{6} \mathrm{mCi} / 27143424 \mathrm{~m}^{3}=0.1040 \mathrm{mCi} / \mathrm{m}^{3}$, perfectly detectable directly by liquid scintillation.

The following data were considered to confirm the estimated Activity of the tracer to be used in the experiments. 


\begin{tabular}{|l|c|}
\hline \multicolumn{1}{|c|}{ Parameter } & Value \\
\hline Maximum distance from injection to sampling & $3500 \mathrm{~m}$. \\
\hline Porosity (conservative estimation) & 0.4 \\
\hline Saturation of water (conservative estimation) & 0.3 \\
\hline $\begin{array}{l}\text { Average layer thickness (information from the } \\
\text { company) }\end{array}$ & $6.0 \mathrm{~m}$. \\
\hline Volume involved (computed above) & $27143424 \mathrm{~m}^{3}$ \\
\hline
\end{tabular}

When Tritium is used as tracer, samples are measured by liquid scintillation. The necessary parameters of the equipment to establish the detection limit are showed below: ${ }^{[4]}$

\begin{tabular}{|l|c|}
\hline \multicolumn{1}{|c|}{ Parameter } & Value \\
\hline Background & $0.033 \mathrm{CPS}(2 \mathrm{cpm})\left({ }^{*}\right)$ \\
\hline Efficiency & $\begin{array}{l}0.28 \text { counts } \\
\text { disintegration }\end{array}$ \\
\hline Measuring time & $10 \mathrm{~min}$. \\
\hline Sample volume & $50 \mathrm{~mL}$ \\
\hline Detection Limit & $4.67 \mathrm{~Bq} / \mathrm{L}$ \\
\hline
\end{tabular}

(*) Estimated for common liquid scintillation equipment $<6$ UT (Tritium Units)

The Detection Limit is calculated by the use of the following equation:

$$
L_{d}=\frac{2,8 \sqrt{N_{F}}}{\text { et } V_{m}}
$$

$\mathrm{L}_{\mathrm{d}}=2.8 *(0.033 * 60 * 10)^{1 / 2} / 0.28 * 10^{*} 60 * 0.05=1.48 \mathrm{~Bq} / \mathrm{L}$ (equivalent to $12.4 \mathrm{UT}$ ) ${ }^{*}$

Considering $3 \mathrm{~Bq} / \mathrm{L}$ (around three times the detection limit), as an average concentration of the water body in which all the injected tracer is dissolved water volume, we find an Activity equal to $81.08 \times 10^{9} \mathrm{~Bq}$ or $2.2 \mathrm{Ci}$. This result confirms that the estimation of the Activity of tritiated water to be injected $(2.5 \mathrm{Ci})$ was correct.

\section{ON FIELD EXPERIMENTS}

The injection system was prepared to release the tracer in a short term of about two minutes, for both tailing deposits. The volume of tracer was $5 \mathrm{ml}$ with 2.5 Curies of total Activity, in 4,0 L. of the same water from the tailing deposit. (Figure 1 additionally shows the prepared injection system). 


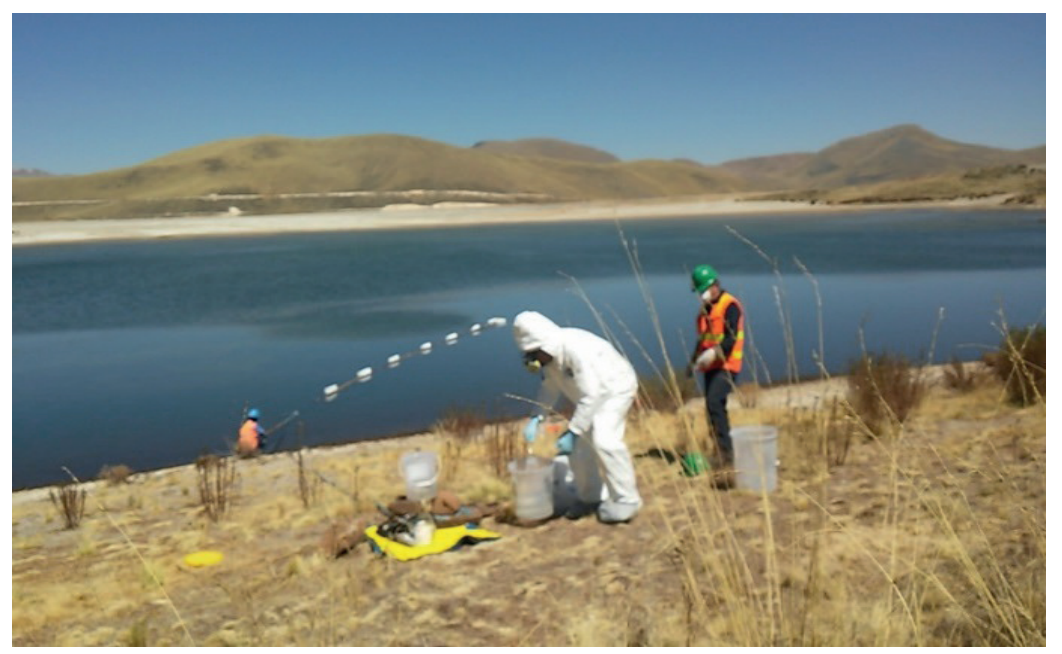

Fig. 1 Preparation of the tracer injection system at Tailing deposit number I

According to the establish schedule, the next day, after the tracer injection in Tailing deposit number I, injection in Tailing deposit number II, was realized, even with problems as a result of the fact that there was no water in the reservoir, as it was in the previous inspection some weeks before.

Since there was not a water mirror in Tailing deposit number II, some other injection technique could cause a change in the natural conditions in the dynamic of the tracer as there would not exist a hydrostatic head to charge or force the percolation of the tracer, with serious influence in the residence time among other parameters of the system.

It was decided to study the results of tomographic studies performed in the previous days with clear indications of the zones with the highest permeability in the base of the dry deposit. Finally, an injection point was selected in a high permeability point. An excavation of a $4 \mathrm{~m}$. depth was performed, then the injection of $2.5 \mathrm{Ci}$ of tritiated water covering with additional water and completed the rest with the same material taken from the deposit, until completing the surface of the deposit. An especially conditioned truck with a tank carrying water from the processing plant poured water during some weeks, in the same place where the tracer was injected, in order to keep a head of charge to allow the tracer migrate at least to the dynamic water level of the tailing deposit.

Taking into account the result of tritium analysis, the data processing by the aid of the software DTR- $8^{[3]}$, indicates the presence of artificial tritium in one point of the monitoring selected points. (figure 2). 


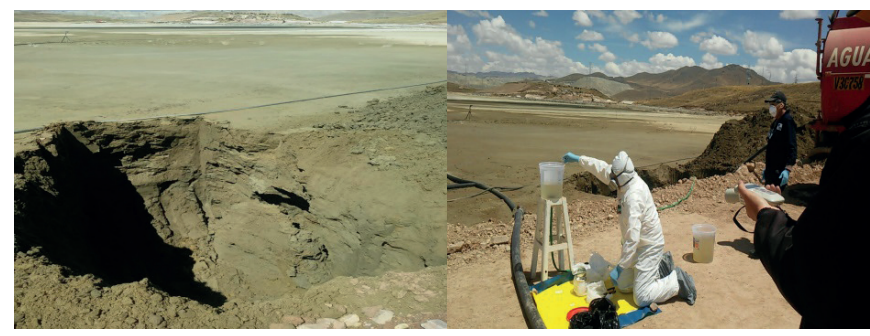

(a)

(b)

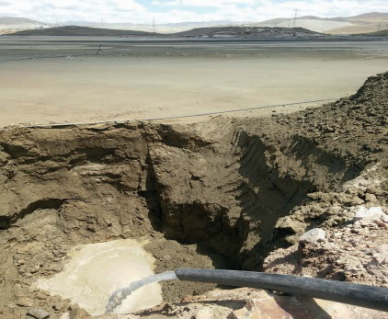

(c)

Fig .2 Tailing deposit number II: Excavation prepared in high permeability area, for tracer releasing

\section{RESULTS}

The following table shows the balance of the radiotracer which appears in the response curve, at the point of the neighborhood of Tailing deposit number I. [14], [15]

\begin{tabular}{|c|c|c|c|c|c|c|c|c|}
\hline $\begin{array}{c}\mathrm{t} \\
\text { (days) }\end{array}$ & $\begin{array}{l}\text { Average } \\
\text { back- } \\
\text { ground, } \\
\text { UT }\end{array}$ & $\begin{array}{c}\text { UT, } \\
\text { measured }\end{array}$ & $\begin{array}{l}\text { UT, } \\
\text { net } \\
(*)\end{array}$ & $\begin{array}{l}\text { Specific } \\
\text { Activity, } \\
\text { Asp., } \\
\text { Bq/L }\end{array}$ & $\begin{array}{l}\text { Specific } \\
\text { Activity, } \\
\text { pCi/L }\end{array}$ & $\begin{array}{c}\Delta t \\
\text { (days) }\end{array}$ & $\underset{(L / s)}{Q}$ & $\begin{array}{c}\text { Activity }= \\
\underline{\mathrm{Q}(\mathrm{L} / \mathrm{s})^{*} \mathrm{Asp} .(\mathrm{pCi} / \mathrm{L})^{*} \Delta \mathrm{t}(\mathrm{s}),} \\
10^{12} \mathrm{pCi} / \mathrm{Ci}, \\
\text { in Curies (Ci) }\end{array}$ \\
\hline 0 & 4 & 4.0 & 0 & 0 & 0 & 0 & 8.0 & 0 \\
\hline 12 & 4 & 6.0 & 2.0 & 0.2384 & 6.442 & 12 & 8.0 & 0.0000535 \\
\hline 24 & 4 & 4.0 & 0 & 0 & 0 & 12 & 8.0 & 0 \\
\hline 50 & 4 & 71.7 & 67.7 & 8.0692 & 218.06 & 13 & 8.0 & 0.0019594 \\
\hline 64 & 4 & 29.0 & 25.0 & 2.9798 & 80.53 & 14 & 8.0 & 0.0007792 \\
\hline 81 & 4 & 4.0 & 0 & 0 & 0 & 17 & 8.0 & 0 \\
\hline \multicolumn{8}{|c|}{$\begin{array}{l}\text { Total Activity of the recovery tracer in the period from } 06.07 .2016 \text { to } \\
06.10 .2016\end{array}$} & 0.0027921 \\
\hline
\end{tabular}

Since the Activity of the tritiated water injected in some point in the neighborhood of Tailing deposit number I, was $2.5 \mathrm{Ci}$. This means that during the 18 months monitoring period, $0.0027921 \mathrm{Ci}$ the point of the neighborhood of Tailing deposit number I, in such a period. Then, the accumulated Activity registered at the tracer cloud in the monitoring point, results in:

$$
(0.0027921 / 2.5) \times 100=0.1112 \%
$$

\section{CONCLUSIONS}

Finally, we arrived to the following conclusions:

a. At present, it is evident the presence of artificial tritium in the neighborhood of the point of Tailing deposit number $\mathrm{l}$. 
b. Taking into consideration the mean residence time of the tracer cloud and the complete response curve, the fraction of tritium in the point of Tailing deposit number I appears after 317 days from the first measuring and remains flowing by such a point during the next 40 days in small pulses.

c. The mass balance of the recovery tracer by the point of Tailing deposit number I, indicates that the same represents $0.1112 \%$ of the total Tritium Activity injected, and remains flowing in the interval from 264 to 330 days from the first measuring moment.

d. In the case of the point of Tailing deposit number II, there is no tritium appearing until this moment. However, the high conductivity encountered in some points of the monitoring area, ranging from 2720 to $3380 \mu \mathrm{S} / \mathrm{cm}$ as well as a clear high concentration of $\mathrm{Cl}^{-}, \mathrm{SO}_{4}{ }^{2-}$ and $\mathrm{Na}^{+}$, indicates that exist high probability that such values could correspond to waters from some monitoring point of Tailing deposit number II.

\section{Case study II: DETERMINATION OF FLOW VELOCITIES IN GROUNDWATER BY THE AID OF TRACER TECHNIQUES}

\section{INTRODUCTION}

The present study corresponds to the evaluation of the groundwater resources in Ica Region at the southern Peru, and reports methodologies and techniques developed for on-site artificial tracer aided measurements of groundwater flow velocities. Horizontal flows are computed through labeling of the whole water column which is coated with a holed pipe in its entire length, below the piezometric level. Concentration monitoring inside the well, is performed prior to the experiment.

The objective of the study was to determine the velocity of water flow, by the aid of tracer techniques, as applied to single well, in order to contribute to the solution of the problem of the aquifer management.

\section{FUNDAMENTALS}

The injection of a tracer in a borehole located in the influence area of the study, allowed the determination of velocity of ground water flow. The basis of the technique relates to the application of a relationship existing between the observed concentration decreases of a tracer solution released into the borehole. Changes in the position of the tracer as a function of time, allow us to draw some conclusions about the direction of flow as well.

Groundwater flows through porous subsurface saturated layers to lower levels than the infiltration ones, and it can arise naturally as springs and rivers contributing flows. Groundwater can be found almost everywhere, either in 
moisturized, semi-arid or arid areas as it is the case of Ica Region. Ica groundwater is an important resource, but it is difficult to manage due to their sensitivity to pollution and overexploitation.

This study is related to the methodology of artificial tracers for determination of flow velocities of groundwater in unique well, having conducted experiments in the a well in the area under study. The technique can be applied when we have wells through which water can move more or less freely, when wells are not ducted, when the lithology of the ground permit the application, or in wells coated with grooved pipe throughout the section covered by the saturated zone (it is better to hole the all length).

The inside diameter of the well under investigation was of the order of 20 inches. However, the technique derived below can also be applied in wells with varied inside diameter.

Horizontal speed of the groundwater flow can be obtained from the decrease of the concentration of some injected tracer, as a function of time, in a given volume of a well, as a result of a perpendicular circulating flow. Let us suppose, that in a section of a well water column with height $h$ and diameter $d$, defined by two perfect closing "packers", is injected a certain amount of tracer, giving an initial concentration Co. It is assumed that the following conditions are met:

(a) That the water flow circulating through the well has a steady-state.

(b) That on the cylindrical volume $V=\pi d^{2} / 4$ of the considered section, the distribution of the tracer is preserved homogeneous, i.e., at any time, the concentration in all points of this volume is the same. This implies that it is found the condition of good mix or instantaneous mixing of the water that enters the volume V.

(c) That the tracer output from volume $\mathrm{V}$ only takes place as a result of the horizontal flow of the aquifer.

The experimental technique for measurement of groundwater flow velocity is based on the method of labelling the entire column. This consists in injecting into the water column, a soluble and easily detectable tracer in water, and monitoring its movement in other nearby wells or the same injected well. The method assumes that the tracer velocity is equal or very similar to the speed of the water. ${ }^{[10],[11]}$

The method consists in introducing a suitable tracer in a well, and observe the decrease of its concentration as a function of time. The variation of concentration depends mainly on any type of flow that exists inside the well and on a lower scale of dissemination of the tracer.

The decrease of homogeneously distributed tracer concentration in a well water column, as a function of time, is defined by the differential equation: (in the absence of vertical flow and significant losses of tracer osmotic diffusion, i.e. by existing diffusion derived from an existing concentration gradient between the water from the well and the water from the aquifer. ${ }^{[19]}$ 


$$
\frac{d C}{d t}=-\frac{C}{V} \frac{d V}{d t}=Q \frac{C}{V}
$$

The solution of equation (1) leads to the expression:

$$
Q=\frac{V}{t} \ln \frac{C_{0}}{C_{t}}
$$

where:

$\mathrm{C}=$ concentration of tracer.

$\mathrm{t}=$ time elapsed at the moment of measurement.

$\mathrm{V}=$ volume of the considered section.

$\mathrm{Q}=$ volume flow.

Equation (2) can also be expressed as:

$$
\mathrm{v}=\frac{\mathrm{V}}{\mathrm{S}} \ln \frac{\mathrm{C}_{0}}{\mathrm{C}}
$$

where:

$\mathrm{v}=$ velocity of water flowing through the well.

$\mathrm{V}=$ Volumen of the considered section.

$\mathrm{S}=$ Section of the $\mathrm{V}$ volumen in the direction of the real flow.

$\mathrm{C}=$ Concentration of the tracer a1 after a time $\mathrm{t}$.

$\mathrm{Co}=$ Inicia1 concentration of the tracer.

The velocity $\mathrm{v}$ is related to the speed of the water in the aquifer by the relationship:

$$
\mathbf{v}=\mathbf{a v}
$$

Where $a$ is a factor that represents the hydrodynamic perturbation caused by the well aquifer and $v$ is the speed of the flow of water in the aquifer. The equation then takes the form:

$$
v=\frac{\mathrm{V}}{\mathrm{S} \alpha} \ln \frac{\mathrm{C}}{\mathrm{C}_{0}}
$$

If the well diameter is $\mathrm{d}$ and the height of the water labeled column is $\mathrm{h}, \mathrm{V}$ volume will be:

$$
V=\pi\left(\frac{d}{2}\right)^{2} h V=\pi\left(\frac{d}{2}\right)^{2} h
$$

and:

$$
\frac{C}{c_{0}}=e^{-\frac{s v \alpha}{V} \frac{C}{C_{0}}}=e^{-\frac{s v \alpha}{V}}
$$

From here it follows that $\mathrm{t}_{1 / 10^{\prime}}$ time required for the concentration of the liner is reduced to $10 \%$ of its initial value, is given by the expression:W 


$$
t_{1 / 10}=\frac{1,81 d}{\alpha v}
$$

Then:

$$
v=\frac{1,81 d}{\alpha t_{1 / 10}}
$$

Where:

$\mathrm{d}=$ Inside diameter of the well.

$\mathrm{A}=$ Factor of hydrodynamic perturbation caused by the well in the aquifer, in relation to the natural flow pattern.

$\mathrm{t}_{1 / 10}=$ Time required to reduce to $10 \%$, the concentration of the tracer in the labelled volume.

$\mathrm{v} \quad=$ Velocity of water in the aquifer.

Coefficient a depends mainly on the well coating conditions, casing and filter conditions, and can be evaluated if it is known or determined experimentally. a values varies between 1 and 3 .

\section{ON FIELD EXPERIMENT}

Figure 1 shows a view of the well in which the present investigation took place.

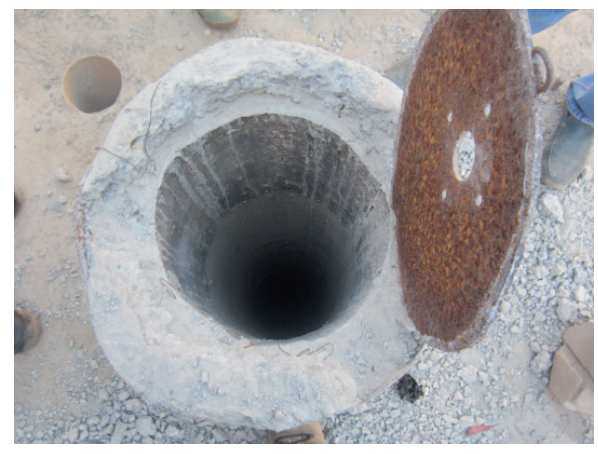

FIG.1 View of the well for the investigation of flow velocities in groundwater.

The applied technique of single well consisted of the injection of tracer in the well and monitoring conductivity for a period of 7 hours, time which depends on the hydrogeological characteristics of the aquifer. The procedure consisted of injecting certain amount of tracer along the entire column of the studied well, in such a way that its concentration becomes uniform (Figure 4). Then conductivity was measured along the labelled column, at different heights. Measures were performed periodically in the same positions until the concentration is extinguished or reached sufficiently low value. 
Labelling throughout the entire water column was realized introducing a plastic hose opened by both extreme and fitted with a ballast at its lower end, to facilitate the dive to the bottom. The solution of tracer consisting of a saturated solution of sodium chloride, equal to the internal volume of the hose (between the bottom and the piezometric level) was then poured on top. This labelled volume completely displaces the water contained inside the hose. The hose was subsequently removed slowly and with constant speed, to allow the water column becomes labelled more or less uniform.

The labelling procedure is illustrated in Figure 2a. The plastic hose was introduced to the bottom well, by the aid of small ballast attached to its lower end. Later on, conductivity profiling was performed, displacing a cable of the conductivity probe and keeping the thermoconductivimeter in surface, as it is shown in figure $2 b$.

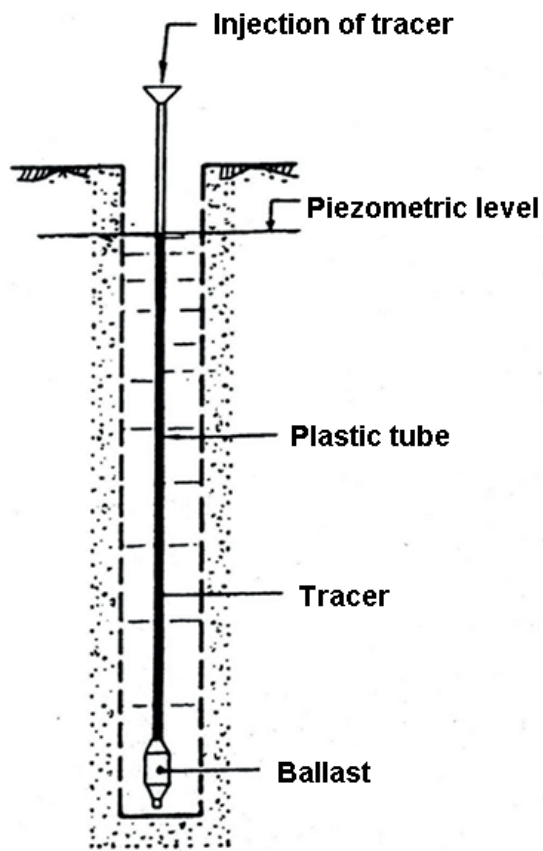

(a)

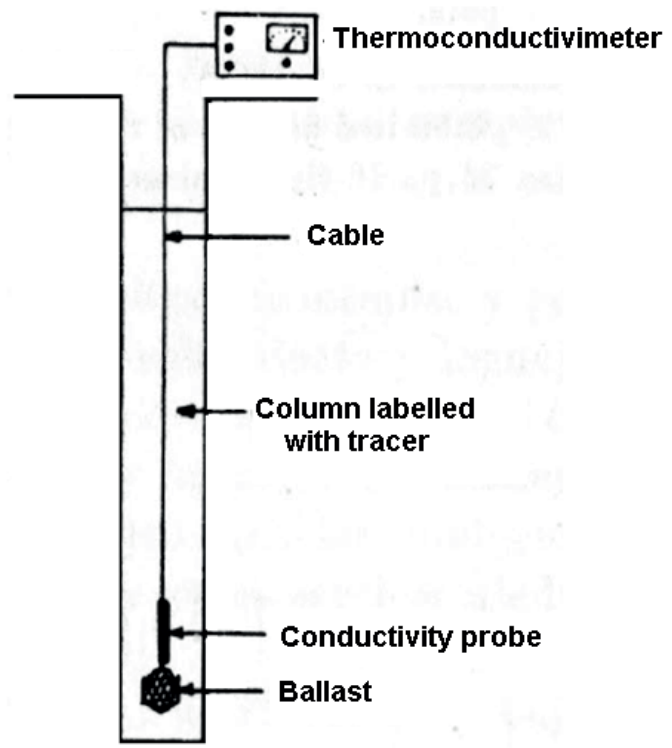

(b)

FIG.2 (a) Method used for the labelling the entire column of water in the well, and (b) Monitoring the tracer for obtaining the conductivity profiles

The hose was open at both ends. By the upper end of the hose, a volume of 6 L. solution of tracer was injected to fill the inside volume, measured from the piezometric level up to the bottom of the well. Then the hose was taken up slowly at an approximately constant speed, to allow the tracer to be distributed uniformly throughout the water column. 
Tracer injection was made by gravity. A saturated solution of common salt was used as tracer, which solubility in water is about $350 \mathrm{~g} / \mathrm{L} .\left(^{*}\right)$.

In this case, we first calculated the volume of solution of common salt required to be injected into the well to get a good distribution in the entire column, and to achieve the desired conductivity. This volume of solution was placed inside a suitable container and injected by moving the hose vertically up and down until the entire volume has been injected. Once the injection of the tracer was finished, it began the action to get successive concentration profiles sweeping the entire column with the probe, at different intervals, for example, $20 \mathrm{~cm}$.

The frequency of the profiles was conducted in accordance with the rate of dilution of the tracer. It began with a higher frequency, for example, every 5 minutes, which was subsequently modified depending on the speed of the tracer dilution.

The hose was filled with solution of tracer in the same manner as indicated above. Then it was taken up the hose assembly and probe on a stretch of 5 meters. When this was done, a section of water column of the well was labelled just 5 meters, and probe was located approximately in the middle of the marked section.

The collected data set allow us to identify the areas where there is horizontal flow in the well. In the section out of the stretch from 60.10 to $64.20 \mathrm{~m}$., there was the area of blind pipe, where it can be seen that there is no loss of tracer since there is no flow. Table 1 show the obtained data in the stretch of interest, while figures 5 and 6 show the curves registering by conductivity and the calculation of the groundwater velocity.

\section{RESULTS}

Table 1. Collected data for registering profiles of Conductivity as a function of well depth at different time intervals (Data for the stretch of interest)

\begin{tabular}{|c|c|c|c|c|c|c|c|c|c|}
\hline \multirow[b]{2}{*}{$\begin{array}{c}\text { Depth, } \\
\text { (m.) }\end{array}$} & \multicolumn{9}{|c|}{ Conductivity, $(\mu \mathrm{S} / \mathrm{cm})$} \\
\hline & $t=0$ & $\begin{array}{l}t=25 \\
\text { a } 35 \\
\text { min. }\end{array}$ & $\begin{array}{c}t= \\
120 \mathrm{a} \\
130 \\
\mathrm{~min} .\end{array}$ & $\begin{array}{l}t=160 \\
\text { a } 170 \\
\text { min. }\end{array}$ & $\begin{array}{c}t=200 \\
\text { a } 210 \\
\text { min. }\end{array}$ & $\begin{array}{l}\mathrm{t}=250 \\
\text { a } 260 \\
\text { min. }\end{array}$ & $\begin{array}{l}t=310 \\
\text { a } 320 \\
\text { min. }\end{array}$ & $\begin{array}{c}\mathrm{t}=370 \\
\text { a } 380 \\
\text { min. }\end{array}$ & $\begin{array}{c}\mathrm{t}=420 \\
\text { a } 430 \\
\text { min. }\end{array}$ \\
\hline 60,10 & * & * & * & * & * & * & * & * & * \\
\hline 60,40 & 3450 & 900 & 850 & 842 & 849 & 842 & 848 & 833 & 843 \\
\hline 60,60 & 3530 & 901 & 853 & 843 & 855 & 844 & 848 & 833 & 843 \\
\hline 60,80 & 3510 & 903 & 855 & 850 & 856 & 842 & 854 & 844 & 850 \\
\hline 61,00 & 3480 & 911 & 859 & 848 & 865 & 853 & 870 & 847 & 860 \\
\hline 61,20 & 3510 & 912 & 887 & 853 & 898 & 855 & 876 & 850 & 879 \\
\hline 61,40 & 3500 & 921 & 905 & 910 & 964 & 860 & 964 & 856 & 940 \\
\hline 61,60 & 3340 & 1101 & 1070 & 965 & 1055 & 940 & 1000 & 940 & 1027 \\
\hline 61,80 & 3350 & 1700 & 1200 & 1130 & 1200 & 962 & 1180 & 1100 & 1172 \\
\hline
\end{tabular}




\begin{tabular}{|l|l|l|l|l|l|l|l|l|l|}
\hline 62,00 & 3350 & 2100 & 2400 & 1820 & 1705 & 1600 & 1700 & 1426 & 1404 \\
\hline 62,20 & 3350 & 3006 & 2580 & 2450 & 2150 & 1900 & 1727 & 1480 & 1480 \\
\hline 62,40 & 3350 & 3800 & 2540 & 1770 & 1708 & 1740 & 1726 & 1490 & 1583 \\
\hline 62,60 & 3360 & 3120 & 2550 & 1800 & 1710 & 1720 & 1726 & 1500 & 1583 \\
\hline 62,80 & 3360 & 3080 & 2560 & 1790 & 1710 & 1720 & 1726 & 1497 & 1580 \\
\hline 63.00 & 3350 & 3000 & 2560 & 1800 & 1715 & 1740 & 1726 & 1497 & 1583 \\
\hline 63,20 & 3540 & 3160 & 2570 & 1800 & 1718 & 1740 & 1727 & 1502 & 1583 \\
\hline 63,40 & 3450 & 3200 & 2580 & 1800 & 1718 & 1750 & 1727 & 1506 & 1577 \\
\hline 63,60 & 3530 & 3230 & 2580 & 1790 & 1718 & 1755 & 1727 & 1511 & 1583 \\
\hline 63,80 & 3510 & 3100 & 2610 & 1790 & 1716 & 1756 & 1729 & 1513 & 1583 \\
\hline 64,00 & 3480 & 3050 & 2610 & 1800 & 1700 & 1760 & 1729 & 1515 & 1583 \\
\hline 64,20 & 3510 & 2980 & 2600 & 1790 & 1714 & 1767 & 1733 & 1515 & 1582 \\
\hline
\end{tabular}

$\left.{ }^{*}\right)$ Out of the water level

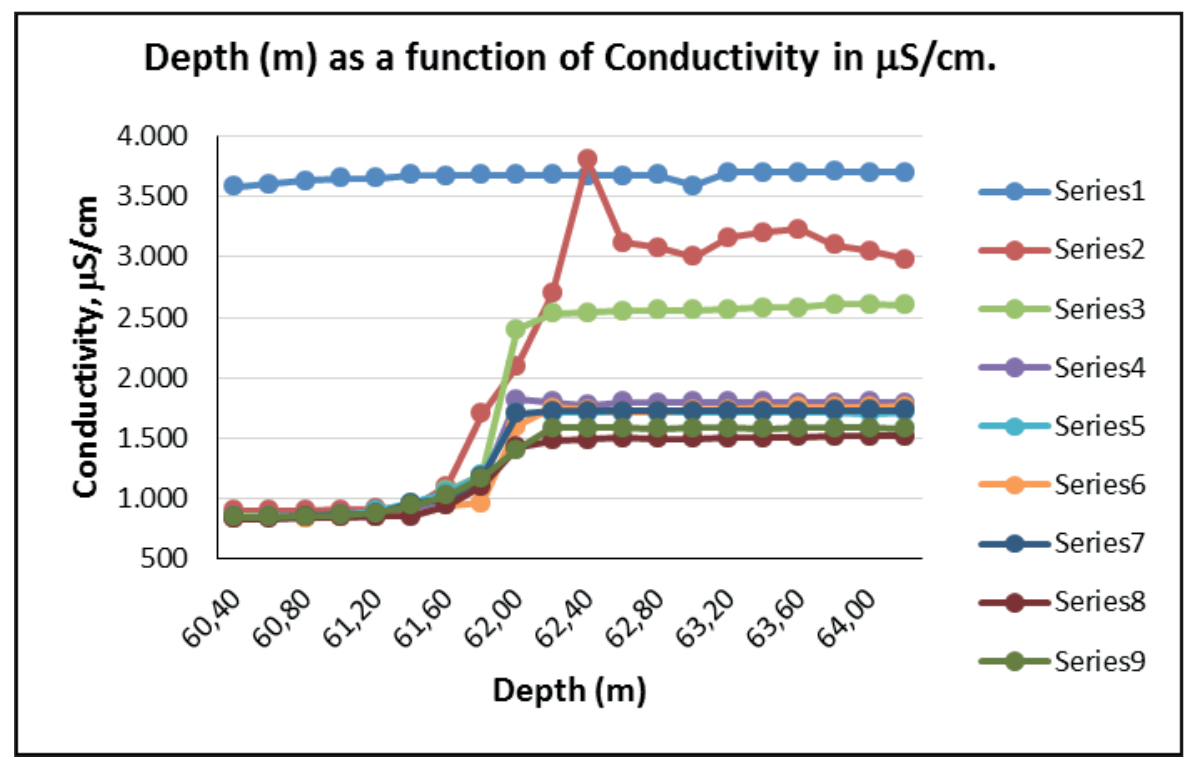

FIG.3 Conductivity Profiles as a function of the depth of the well. In most of the cases, it was observed maximum conductivity values at an average depth of $62.20 \mathrm{~m}$

Series 1: Register at $\mathrm{t}=0$ (start of measurements)

Series 2: Register at $t=30$ minutes $(0.5 \mathrm{~h}$.)

Series 3: Register at $t=125$ minutes $(2.08 \mathrm{~h}$.)

Series 4: Register at $t=165$ minutes ( $2.75 \mathrm{~h}$.)

Series 5: Register at $t=205$ minutes (3.42 h.)

Series 6: Register at $t=255$ minutes $(4.25 \mathrm{~h}$.)

Series 7: Register at $t=315$ minutes ( $5.25 \mathrm{~h}$.)

Series 8: Register at $t=375$ minutes $(6.25 \mathrm{~h}$.)

Series 9: Register at $t=425$ minutes $(7.08 \mathrm{~h}$.) 


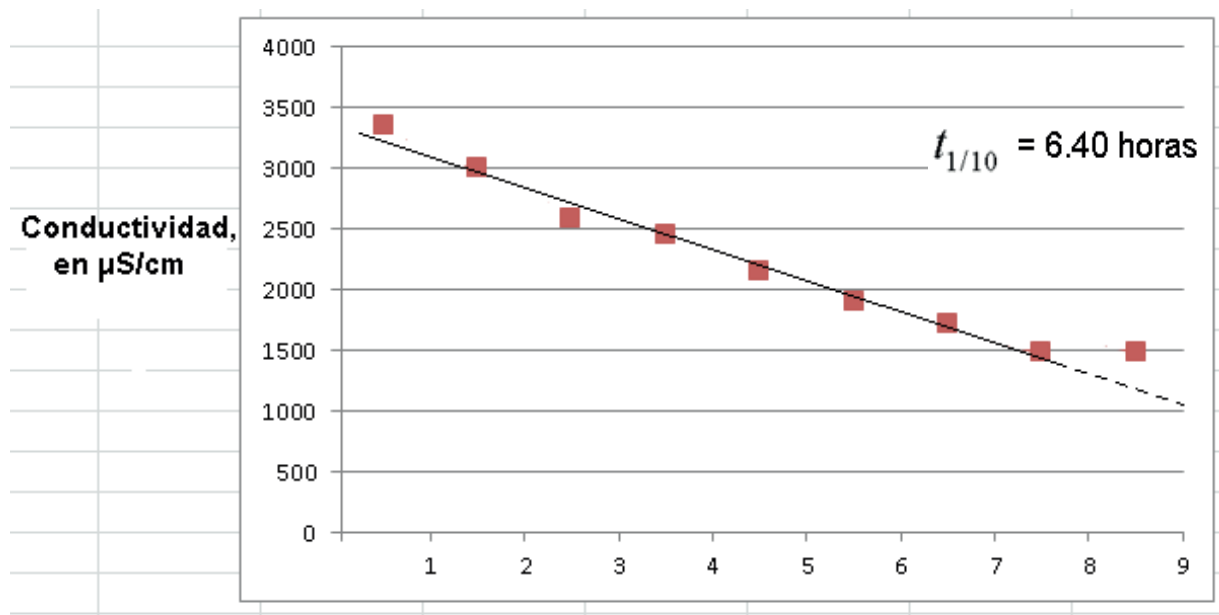

Tiempo, en $\mathbf{h}$.

FIG.4. Conductivity declining curve as a function of time, at the level of horizontal water flow $(62.20 \mathrm{~m}$.). This information is also used to calculate the flow velocity of the groundwater.

Using the equation:

$$
v=\frac{1,81 d}{\alpha t_{1 / 10}}
$$

We finally obtain:

$$
v=\frac{1,81 \times 20 \times 0,0254 \mathrm{~m} .}{1 \times \frac{10,25}{24} \text { day }}=3,44 \mathrm{~m} / \mathrm{day}
$$

\section{CONCLUSIONS}

As a result of the study, we draw the following conclusions:

a. It was not observed the presence of vertical flows. The technique provided the horizontal speed of the underground flow fairly accurately, without making any adjustment to the methodology.

b. Horizontal velocity found in the studied well is $3,44 \mathrm{~m}$. per day. The static level was 25 meters of depth during the measurements.

c. To interpret the results correctly, it was necessary to have information on the constructive aspects of the well. The basic parameters needed are the inside diameter of the well, the characteristics of groove made in the pipe coating and data about possible external filling with gravel.

d. The low variability of the values of the horizontal velocity and the absence of 
vertical flows, corroborates the affirmation that the aquifer is homogeneous and that there are flows concentrated through fractures.

e. Given the importance which means the proper utilization and management of water resources of the area, it is recommended that higher speed levels require a detailed study and adequate management of the aquifer, taking into account the dangers of biological contamination of groundwater, which may result from septic tanks or surroundings to the recharge area.

f. Once known the values of the speed of infiltration and under field conditions, can get parameters such as hydraulic conductivity and transmissibility.

g. It has been established the mainly benefits provided by the use of tracer techniques, including the following: The speed can be determined without knowing the porosity of the aquifer, and only one well is needed to perform the measurements.

h. Speeds from few centimeters per day up to several tens of meters per day can be measured inside the well.

i. Measurements in single wells represent a timely data, which may not be representative of the study area. However, this can be overcome if we carried out measurements in a sufficient number of carefully selected wells.

\section{REFERENCES}

1. CUSTODIO, E., "Hidrología Subterránea, Vol.1, Barcelona, 2001

2. GLOVERTE., ROBERT, "Transient Groundwater Hydraulics", Colorado,USA-2010

3. G.E. MAGGIO-Noldor S.R.L. [1998], Programa DTR 8-Manual de Operación, Argentina.

4. IAEA, "Emerging New Applications of Radiotracers in Industry", ViennaAustria, 1997

5. IAEA, "Radiotracer Technology for Engineering Unit Operation Studies and Unit Processes Optimization". Technical Report, Krakow-Poland, 1999

6. LECLERC J.-P., Grevillot G., "Traceurs et méthodes de traçages”, Récents Progrès en Génie des procédés, 61, Vol. 12, 1998.

7. LECLERC J.-P., "Traceurs and tracing methods", Récents Progrès en Génie des procédés, 79, Vol. 15, 2001.

8. NAZEER, AHMED, "Hydraulics of Wells Design, Construction and Testing", Reston,Virginia-USA, 2014

9. NEVEN, KRESIC, "Hydrogeology and Groundwater Modeling", Bocaraton, Florida-USA, 2007 
10. PLATA, A. (1972). Isótopos en Hidrología. Editorial Alambra. Madrid.

11. PLATA, A., MUNERA, H., SÁNCHEZ, L., ZAPATA,G. (1973). Determinación de las direcciones de flujo en los diez pozos de agua de propiedad de Insfopal. IAN. Informe N9 4, 10 p., 15 figs. (Mimeografiado). Instituto de Asuntos Nucleares. Bogotá.

12. RODRíGUEZ, C. O. (1972). Análisis hidrogeológico de la Cuenca Central de la isla de San Andrés, 12 p., 3 figs. (Mimeografiado), Instituto de Asuntos Nucleares. Bogotá.

13. RODRÍGUEZ, C. O. (1973). Determination of aquifer parameters with radiotracers, Submited as part of the first term, $\mathrm{M}$. Sc. course requirements in hydrogeology. 33 p., 10 figs. University of London-UK.

14. SEBASTIAN C. Y OTROS "Normas y Procedimientos sobre Tecnología de Trazadores".- IPEN-Perú, Agosto, 1999.

15. SEBASTIAN C., MAGHELLA G., MAMANI, E. MAGUIÑA J. [2004] "Overview of radiotracer experiments for better understanding of wastewater and water treatment plants in Lima (Perú)", Revista del INCQ-Nancy-Francia.

16. SEBASTIAN C., MAGHELLA G., MAMANI, E. MAGUIÑA J. [2004] Tracer and Tracer Methods, Warsawa-Poland.

17. SEBASTIAN C., MAGHELLA G., MAMANI, E. MAGUIÑA J. [2007] Interpretation of radiotracer experiments in an industrial battery of desanders with simultaneous stochastic and non-stochastic flows, Applied Radiation and Isotopes-USA.

18. THERESKA, J., "Radiotracer Methodology and Technology".- IAEA, NAPC, Industrial Applications and Chemistry Section, Vienna-Austria, February 1999.

19. ZEKAI SEN, “Practical and Applied Hydrogeology”, Waltham, MA-USA, 2014 